\title{
Screening of lonic Liquids for Keratin Dissolution by Means of COSMO-RS and Experimental Verification
}

Liu, Xue; Nie, Yi; Liu, Yanrong; Zhang, Suojiang; Skov, Anne Ladegaard

Published in:

ACS Sustainable Chemistry and Engineering

Link to article, DOI:

10.1021 /acssuschemeng. $8 \mathrm{~b} 04830$

Publication date:

2018

Document Version

Peer reviewed version

Link back to DTU Orbit

Citation (APA):

Liu, X., Nie, Y., Liu, Y., Zhang, S., \& Skov, A. L. (2018). Screening of lonic Liquids for Keratin Dissolution by Means of COSMO-RS and Experimental Verification. ACS Sustainable Chemistry and Engineering, 6(12), 17314-17322. https://doi.org/10.1021/acssuschemeng.8b04830

\section{General rights}

Copyright and moral rights for the publications made accessible in the public portal are retained by the authors and/or other copyright owners and it is a condition of accessing publications that users recognise and abide by the legal requirements associated with these rights.

- Users may download and print one copy of any publication from the public portal for the purpose of private study or research.

- You may not further distribute the material or use it for any profit-making activity or commercial gain

- You may freely distribute the URL identifying the publication in the public portal 


\title{
Screening of ionic liquids for keratin dissolution by
}

\section{means of COSMO-RS and experimental verification}

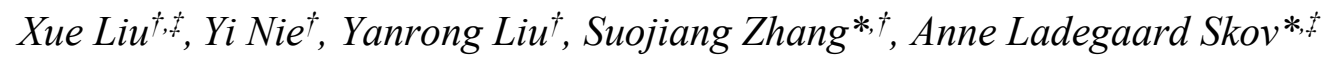

${ }^{\dagger}$ Beijing Key Laboratory of Ionic Liquids Clean Process, Key Laboratory of Green Process and Engineering, State Key Laboratory of Multiphase Complex Systems, Institute of Process Engineering, Chinese Academy of Sciences, P.O. Box 353 Beijing, 100190, China.

*Danish Polymer Centre, Department of Chemical and Biochemical Engineering, Technical University of Denmark, Søltofts Plads 227, 2800 Lyngby, Denmark.

Corresponding Author: E-mail: al@kt.dtu.dk, sjzhang@ipe.ac.cn 


\section{ABSTRACT}

It is a challenging undertaking to screen the best ionic liquid for keratin dissolution, due to the complexity of keratin molecules and the variety of ionic liquids (ILs). Herein, three keratin models and 621 ILs, including 27 cations and 23 anions, were used to evaluate keratin dissolution capability via a screening method based on COSMO-RS. From the prediction results of logarithmic activity coefficients $(\ln \gamma)$ for the three keratin models, it can be concluded that anions play a leading role in keratin dissolution, while cations only have a moderate effect on the dissolution process. The hydroxyl group on the cation side chain has a significant effect on the keratin dissolution capability of ILs. In addition, the experimental solubility of wool keratin in ten ILs was used to verify the theoretical predictions. Experimentally determined keratin solubility agrees well with the predicted $\ln \gamma$. The residual sum of squares (RSS) and R square $\left(\mathrm{R}^{2}\right)$ between the $\ln \gamma$ of three keratin models and keratin solubility illustrate that the models glutathione (GSSG) and polypeptide (PP) represent keratin better than cystine (CYS). $\mathrm{Ac}^{-}, \mathrm{Dec}^{-}, \mathrm{HCOO}^{-}, \mathrm{Cl}^{-}, \mathrm{BEN}^{-}$, $\mathrm{DMP}^{-}, \mathrm{DEP}^{-}, \mathrm{DBP}^{-}, \mathrm{TOS}^{-}$and $\mathrm{Br}^{-}$, with the various cations studied in this work, exhibited particularly good properties for keratin dissolution. Excess enthalpy calculations indicated that the main forces in keratin dissolution in ILs are H-bonds, while the contribution of misfit forces and van der Waals forces is a secondary factor.

KEYWORDS: Keratin, Screening, Ionic liquids, dissolution capability, H-bond 


\section{INTRODUCTION}

Keratin, a natural fibrous protein, has significant application value in many fields, due to its excellent performance in areas such as biodegradability, biocompatibility and stability. ${ }^{1}$ It is abundantly available as the main composition of wool, feathers, hairs and animal horn. ${ }^{2}$ These properties have led to the rapid development of keratin-based materials in the field of biodegradable fibres, biocompatible film and biomedical devices, amongst others. ${ }^{3-5}$ Wool keratin, which consists of about $95 \%$ pure keratin, is one of the most important sources; ${ }^{6}$ however, secondary pollution and resource waste are caused by low-grade and waste keratin textiles. ${ }^{7}$ Therefore, it is an urgent and challenging necessity to use waste keratin for functional biomaterials. Unfortunately, the tight packing of secondary structures in the polypeptide, aligned with strong inter- and intra-molecular hydrogen bonds and disulphide bonds, renders keratin insoluble in common organic solvents. ${ }^{8-9}$

In order to extract the protein, several traditional methods, such as oxidation, ${ }^{10}$ reduction ${ }^{11}$ and sulfitolysis, ${ }^{12}$ have been investigated in terms of dissolution. While these methods are efficient in obtaining keratin, they also lead to its degradation and serious environmental pollution. These limitations have inspired researchers to develop new and efficient solvents. Ionic liquids (ILs), which can be considered green solvents, can effectively extract keratin from biopolymers due to their remarkable properties, especially their tuneable structure. ${ }^{13-15}$ Promising results have been published in this regard. ${ }^{7,13,16}$

As previously reported, ILs with an imidazolium cation show significantly high keratin dissolution capability, while ILs with tetrabutylammonium and tetrabutylphosphonium cannot achieve this task. ${ }^{6,17}$ The side chain length has a slight influence on keratin dissolution capability, but the hydroxyl group on the cation side chain has a significant effect in this regard, due to the 
formation of intramolecular hydrogen bonds between keratin molecules and ILs. ${ }^{6}$ The most efficient anions for keratin dissolution are acetate, formate, phosphate and chloride. ${ }^{7,}$, 13, 16-18 Some researchers state that keratin dissolution in ILs is an anion-dependent process,${ }^{19}$ while others claim that both cations and anions play a role. ${ }^{6,17}$ Moreover, Zhang et al. ${ }^{17}$ found that the breakage of disulphide bonds has a significant effect on the keratin dissolution process. The results reported by Liu et al. ${ }^{18}$ also support this conclusion. Although there have been extensive studies on keratin dissolution in ILs, it is still a huge challenge to identify the best IL for this undertaking; for instance, the experimental measurement of these systems is not practically feasible, due to the very large number of combinations, and so an effective screening method to predict keratin dissolution capacity for ILs is needed.

COSMO-RS, a well-defined method for predicting the thermophysical properties of liquids, is a useful tool for predicting the solubility of polymers through the hypothesis that polymers can be treated as solutions consisting of monomers or oligomers with a small number of repeat units. ${ }^{20}$ It has also attracted a significant amount of attention in terms of ILs, as it integrates the dominant interaction forces of H-bonds, misfits and van der Waals in ILs systems. ${ }^{21-22}$ Many results on the prediction of polymer properties in ILs have been reported, and it is obvious that calculating the activity coefficients, ${ }^{23}$ solubility coefficients ${ }^{1,24}$ and excess enthalpy ${ }^{25}$ of polymer in ILs is an effective way of evaluating the dissolution ability of the ILs. Casas et al., ${ }^{26}$ for instance, found that the solubility of cellulose and lignin could be accurately predicted by using activity coefficients and excess enthalpy via COSMO-RS. A study by Christoph et al. ${ }^{20}$ also reported the high predictive accuracy of activity coefficients, solubility coefficients and partition coefficients obtained from COSMO-RS. However, no results about forecasting keratin solubility in ILs have 
been reported so far, perhaps because keratin molecules do not have regular repeating units, thereby making it difficult to build proper models to represent keratin.

Herein, we select three different models with disulphide bonds to represent keratin. The logarithmic activity coefficients $(\ln \gamma)$ of keratin models in 621 ILs, formed from 27 cations and 23 anions, were predicted to evaluate their ability to dissolve wool keratin by COSMO-RS. Predictive $\sigma$-profiles, $\sigma$-potentials and excess enthalpy were also used to analyse the keratin dissolution capability of ILs. Furthermore, the solubility of wool keratin in ten ILs was measured to verify the prediction results in this work. Experimental verification versus COSMO-RS prediction assisted in identifying the best IL and keratin model.

\section{EXPERIMENTAL SECTION}

\section{COSMO-RS implementation}

All of the COSMO-RS calculations presented in this work were carried out using the commercial COSMOthermX (version C3.0 release 17.01) suite, applied with parameterisation BP-TZVPFINE-C30-1701. ctd, COSMOlogic GmbH \& Co. KG, Leverkusen, Germany. $\sigma$-profiles and corresponding input COSMO-files of cations, anions and molecular solutes can be seen from COSMObase and COSMObaseIL. It is not possible to include all the COSMO files of compounds, but those for the missing ions were created by two steps. First, the ions' structures were optimised by the quantum chemical Gaussian09 package at the B3LYP/6-31++G (d, p) level. In the second step, the optimised structures' files were opened by Gaussian03 and calculated using the BVP86/TZVP/DGA1 level theory to produce input files directly for COSMO-RS calculation.

As previously reported, the cations and anions of ILs are treated as independent components of the mixture when COSMO-RS is employed to calculate activity coefficients. In this work, the molar fractions of the cations and anions of ILs were treated as an equimolar mixture, which helped 
compare the contribution of each counterion in relation to their affinity with the keratin molecule. Whilst calculating logarithmic activity coefficients and excess enthalpies for the solutions, the molar fractions of the ILs cations and anions were set to 0.25 , and the molar fraction of the given keratin model was set to 0.5 . The calculation temperature was set to $120{ }^{\circ} \mathrm{C}$, and experimental verification was performed at the same temperature.

\section{Structures of cations and anions}

According to the work of Zheng et al. ${ }^{6}$ ILs with an imidazolium cation show significant keratin dissolution capability, while ILs with tetrabutylammonium and tetrabutylphosphonium do not. The most efficient anions for keratin dissolution are acetate, formate, phosphate, and chloride. Morpholinium-based, pyridinium-based, and pyrrolidinium-based ILs with the functional groups of ethyl, allyl, 2-hydroxyethyl, 2-methoxyethyl, or acryloyloxypropyl were considered based on the work of Liu et al. ${ }^{22}$ Kuzmina et al. ${ }^{27}$ and Liu et al. ${ }^{18}$ Both concluded that azabicyclo-based superbase ILs possess large potential for dissolving biomass. Idris et al. ${ }^{7}$ indicated that cholinebased ILs could dissolve feather keratin without addition of solvent or other chemicals. In this research, methylimidazolium, pyridinium, ethylmorpholinium, methylpyrrolidinium, azabicyclo and choline with different functional groups were combined with 23 anions resulting in 621 ILs. The total of 621 ILs were selected to assess their ability to dissolve wool keratin via COSMO-RS. The details of their structures and abbreviations are listed in Table 1

Table 1. Chemical structures of cations and anions used in this work

Methylimidazolium




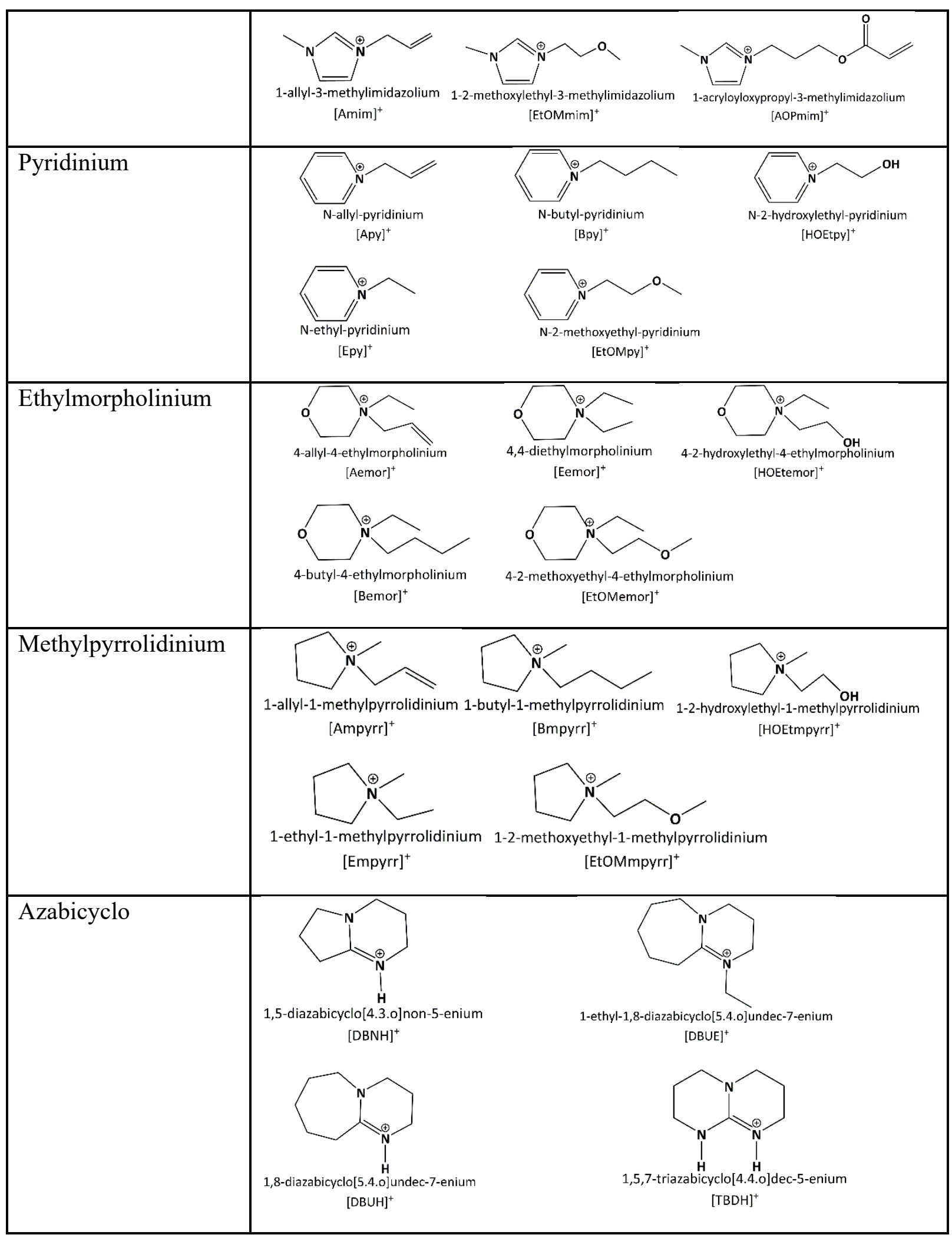




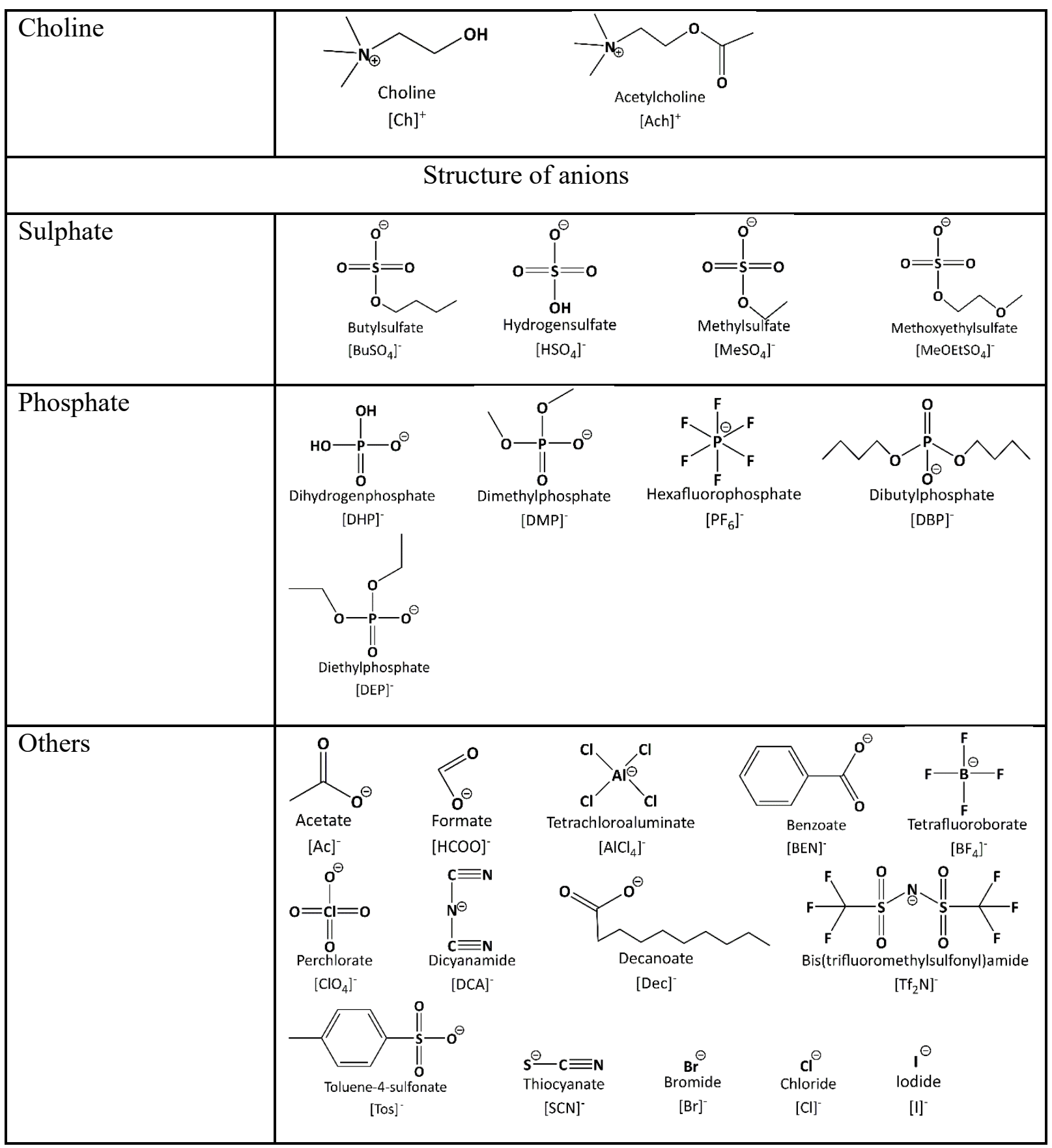

\section{Keratin models}

Keratin is a natural fibrous protein with multiple strong inter- and intra-molecular bonds. Unlike other polymers, keratin molecules have no regular repeating units, which makes it difficult to build a proper model to describe it properly. Based on previous studies, keratin has higher stability and 
lower solubility, due to inter- and intra-chain disulphide bond cross-links. ${ }^{17-18}$ Based on our previous study, we found that the cleavage of disulfide bond plays an important role on keratin dissolution. ${ }^{17}$ In the keratin molecule, disulfide bonds are present in cysteine. So, we selected cysteine (CYS) as the first model to present the keratin. The second model is oxidized glutathione (GSSG), which contains other amino acids with high contents in keratin, except cysteine. A polypeptide (PP), include two cysteine and other amino acids, as the third model. The optimised structures of the three models were obtained according to the procedures described in section 2.1, and along with charge surface regions they are shown in Figure 1.

\section{Chemicals}

Triethyl phosphate ( $\geq 98 \%$ ) was supplied by the Tokyo Chemical Industry Co., Ltd. N-methylimidazole ( $\geq 98 \%$ ) was provided by Sinopharm Chemical Reagent Co., Ltd. 1-ethyl-3methylimidazolium acetate (EmimAC, $\geq 99 \%$ ), 1-allyl-3-methylimidazolium chloride (AmimCl, $\geq 99 \%$ ), N-butyl-pyridinium chloride (BpyCl, $\geq 99 \%$ ), 1-Butyl-1-methylpyrrolidinium chloride (BmpyrrCl, $\geq 99 \%$ ) and 1-2-hydroxylethyl-3-methylimidazolium chloride (HOEtmimCl, $\geq 99 \%$ ) were purchased from Chengjie Chemicals Ltd. 1-ethyl-3-methylimidazolium chloride (EmimCl, $\geq 98 \%$ ) and 1-butyl-3-methylimidazolium chloride (BmimCl, $\geq 98 \%$ ) were purchased from SigmaAldrich. Wool keratin was provided by Henan Zhongrong Biotechnology Co., Ltd.
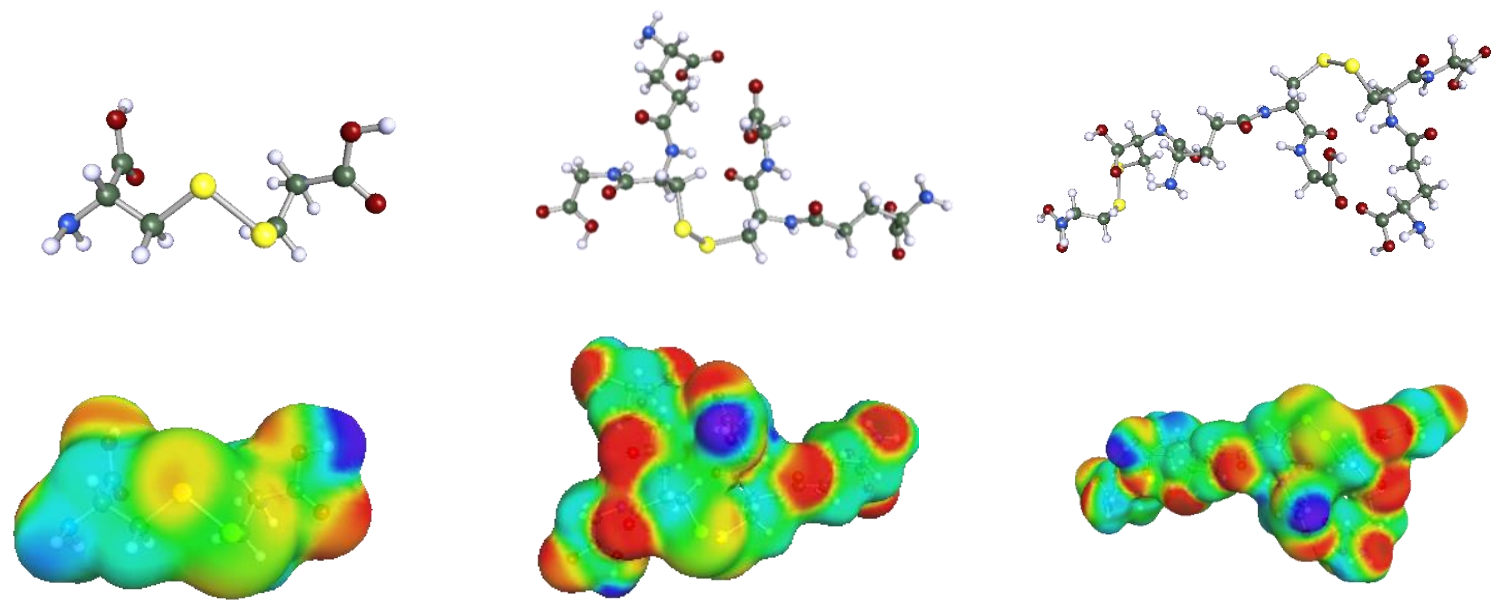
Model 1: Cystine (CYS) Model 2: Glutathione (GSSG) Model 3: Polypeptide (PP)

Figure 1. Optimised structures and charge surface regions of three models. Red zones illustrate positive surface charge, yellow and green zones indicate almost neutral charges, and navy blue designates a negative surface charge.

\section{Experimental apparatus and procedure}

The detailed synthetic procedure for EmimDEP was developed in our laboratory according to procedures described in the literature. ${ }^{28}$ BmimDCA and BmimSCN were synthesised under the previously reported conditions, respectively. ${ }^{29-30}$ Before the experiment, these ILs were purified by using an oil pump vacuum at $353 \mathrm{~K}$ for several days, in order to remove any residual water. The water content of the ILs was measured, before use, with a C20 Coulometric KF Titrator (Mettler Toledo) (Table S1). The purity and structure of these ILs were analysed via NMR, detailed data for which are provided in supporting information.

Wool keratin, which consists of approximately 95\% pure keratin, was used for the verification experiment, in which the wool keratin was added to the ILs, magnetically stirred in a tube at 393 $\mathrm{K}$ and then shattered into small pieces before dissolution. The degree of dissolution at a given time was investigated by using a microscope via light scattering with a $200 \times$ objective lens, and keratin solubility in IL was determined when keratin fibres were not completely dissolved within $24 \mathrm{~h}$.

\section{RESULTS AND DISCUSSION}

\section{$\sigma$-potential of the three keratin models}

Based on the quantum chemical calculation result, COSMO-RS can estimate the thermodynamic properties of a compound(s) via 3D molecular surface polarity distribution. $\sigma$-potential is a thermodynamic property utilised to analyse the affinity of the system to a polarity $\sigma$ surface. The $\sigma$-potential is divided into three main regions, namely the $\mathrm{H}$-bond donor region (where $\sigma<-0.0082$ 
e $\AA^{-2}$ and is related to its ability to interact with hydrogen bond donors), the non-polar region (where -0.0082 e $\AA^{-2}<\sigma<+0.0082$ e $\AA^{-2}$ and is related to its ability to interact with non-polar groups) and the H-bond acceptor region (where +0.0082 e $\AA^{-2}<\sigma$ and is related to its ability to interact with hydrogen bond acceptors). In essence, the more negative the $\sigma$-potential values, the more favourable the interaction. From Figure 2, $\sigma$-potential values for the CYS model are more negative than for the GSSG and PP models in the H-bond acceptor region, which means that CYS results in more affinity for the H-bond acceptor surfaces.

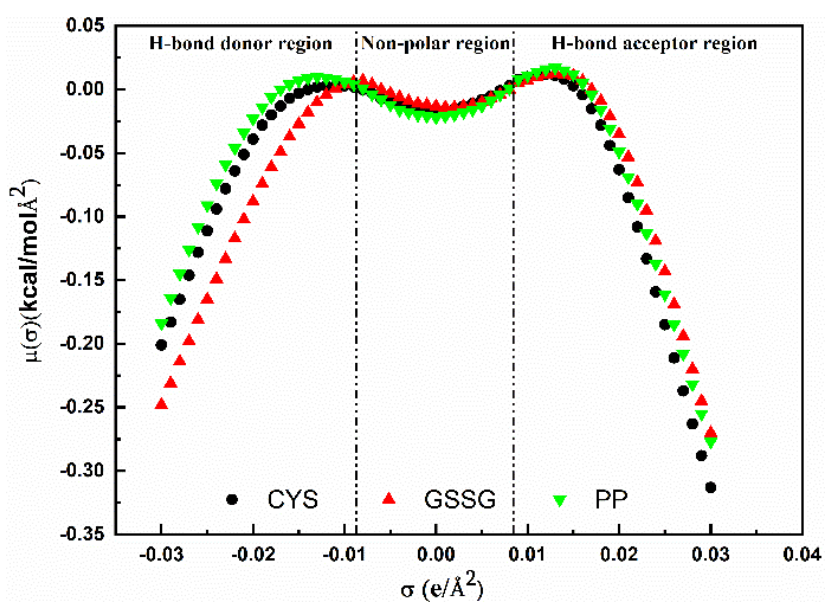

Figure 2. $\sigma$-potentials of three keratin models predicted by COSMO-RS

Furthermore, $\sigma$-potential values for model GSSG are more negative than for the other two models in the H-bond donor region, which means that GSSG causes more affinity for H-bond donor surfaces.

\section{Predicting the logarithmic activity coefficient $(\ln \gamma)$}

The logarithmic activity coefficients $(\ln \gamma)$ of the three keratin models in 621 ILs were predicted, in order to analyse the effect of ILs structure on the solubility of keratin. The results are illustrated in Figure 3-5. The cations and anions are arranged in sequence according to their keratin dissolution ability, which for the cations, from top to bottom, and the anions, from left to right, 
decreases gradually. The best IL for keratin dissolution was placed at the higher-left corner of each of the three figures.

It should be noted that the logarithmic activity coefficient $(\ln \gamma)$ sequence of cations in Figure 3 and Figure 4 is almost identical, while the sequence of the cations in Figure 5 is slightly different. The $\ln \gamma$ order of the anions from the three keratin models is almost the same. From Figure 3-5, the ILs with the methylpyrrolidinium cation have a lower predicted $\ln \gamma$ than the others, while ILs with anions $\mathrm{Ac}^{-}, \mathrm{Dec}^{-}, \mathrm{HCOO}^{-}, \mathrm{Cl}^{-}, \mathrm{DEP}^{-}, \mathrm{DMP}^{-}, \mathrm{DBP}^{-}, \mathrm{BEN}^{-}, \mathrm{Br}^{-}$or $\mathrm{TOS}^{-}$also have a lower $\ln \gamma$, thereby suggesting that they have high keratin dissolution capability. Furthermore, the $\ln \gamma$ of these three keratin models in different ILs with varying cations matches closely; however, the structures of ILs are different. The slight difference in $\ln \gamma$ is due to the effect caused by the cations. Conversely, there is a big difference between the ln $\gamma$ of these three keratin models in different ILs with varying anions, thus indicating that the keratin dissolution capacity of ILs is indeed affected by cations and anions, albeit the anion plays a leading role in this regard. These findings are in accordance with the conclusion of previous reports. ${ }^{19,31}$ Wang et al. ${ }^{32}$ also reported that the solubility of keratin is related significantly to the polarity of the ILs, and the dissolution capability increases when increasing the polarity of ILs. The detailed logarithmic activity coefficient $(\ln \gamma)$ data from this work are listed in Table S3-S5 in supporting information.

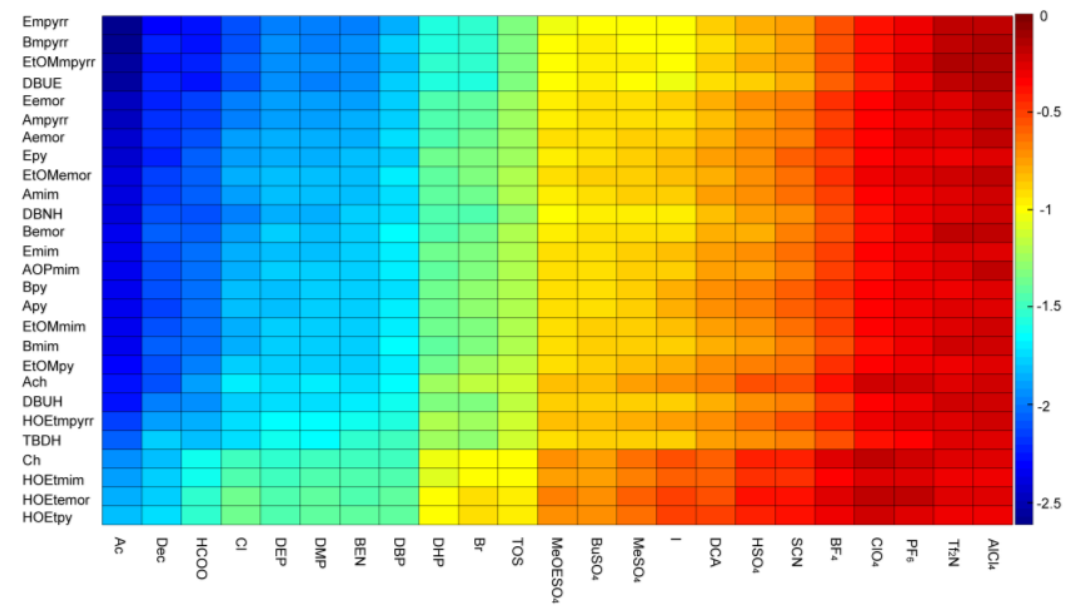


Figure 3. The logarithmic activity coefficients $(\ln \gamma)$ prediction of the CYS keratin model in 621 ILs at $120^{\circ} \mathrm{C}$.

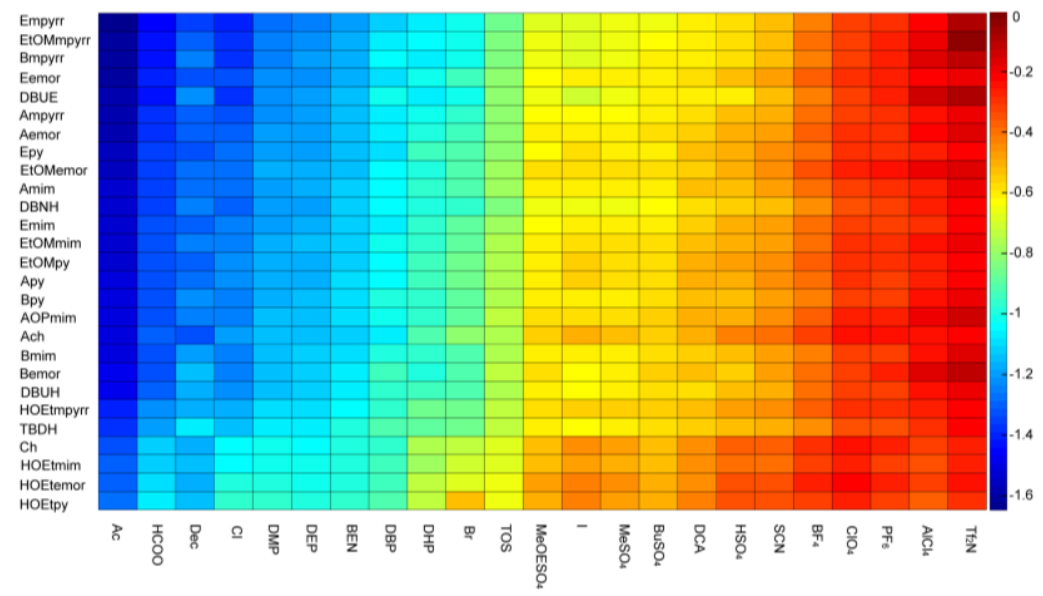

Figure 4. The logarithmic activity coefficients (ln $\gamma$ ) prediction of the GSSG keratin model in 621 ILs at $120^{\circ} \mathrm{C}$.

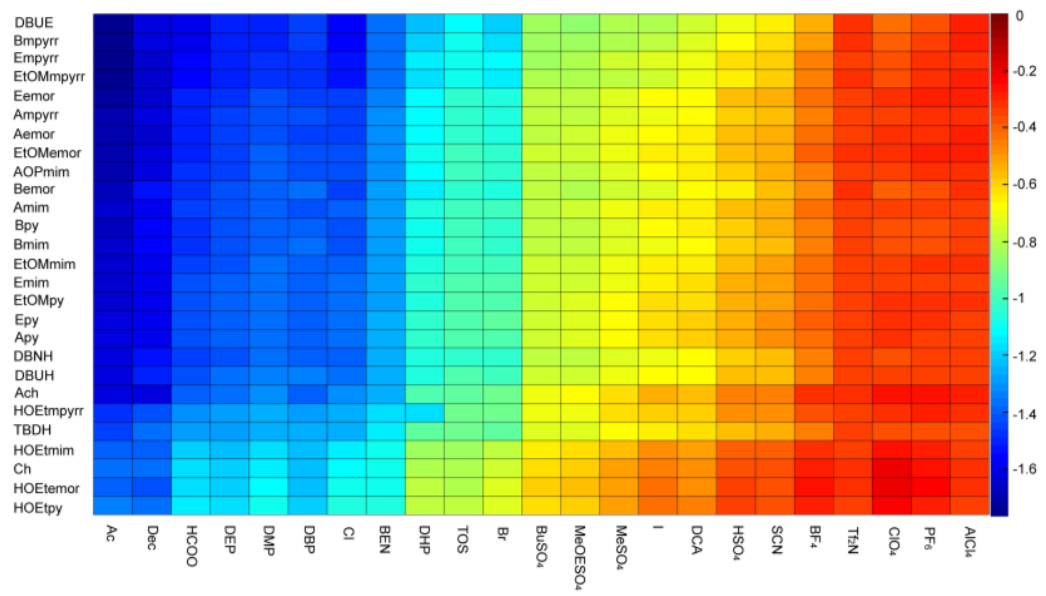

Figure 5. The logarithmic activity coefficients $(\ln \gamma)$ prediction of the PP keratin model in 621 ILs at $120^{\circ} \mathrm{C}$.

\section{Verification experiments}


The solubility of keratin in ten ILs was measured at $120^{\circ} \mathrm{C}$ to validate the COSMO-RS prediction results. In these ten ILs were the functional groups ethyl, allyl, butyl or 2-hydroxylethyl, along with methylimidazolium, methypyrrolidinium and pyridinium selected as cations, and $\mathrm{Ac}^{-}, \mathrm{DEP}^{-}$, $\mathrm{Cl}^{-}, \mathrm{DCA}^{-}$or $\mathrm{SCN}^{-}$as anions. From Table 2, it is evident that the keratin solubility trend in ILs is almost the same as in the logarithmic activity coefficient $(\ln \gamma)$. We also compared our data with the literature values. The results show that our experimental data is reliable. The details of the literature values are shown in supporting information Table S2.

Cation effect. The effect of cation side chain lengths on the dissolution capability of keratin can be analysed from the keratin solubility of $\mathrm{AmimCl}, \mathrm{EmimCl}$ and $\mathrm{BmimCl}$. In this case, in line with the predicted results, the solubility of these three ILs was not much different. This result also indicated that cation side chain lengths do not play a significant role in the dissolution process. Moreover, we found the hydroxyl group in cations has an important influence on the solubility of keratin in ILs, by comparing the keratin solubility of EmimCl and HOEtmimCl. Zheng et al. ${ }^{6}$ explained that the reason for the effect of the hydroxyl group on dissolution capability is the formation of intramolecular H-bonds between ILs and keratin molecules, which reduces the ability to cleave H-bonds between keratin molecules. Unfortunately, when we investigated the effect of the cation host on keratin solubility, it was found that $\mathrm{BmpyrrCl}$ and $\mathrm{BpyCl}$ were solid at $120^{\circ} \mathrm{C}$. This is actually one of the main disadvantages of COSMO-RS, in that the morphology of ILs under simulated conditions cannot be distinguished. Consequently, we tested the solubility of $\mathrm{BmpyrrCl}$, $\mathrm{BpyCl}$ and $\mathrm{BmimCl}$ at $180^{\circ} \mathrm{C}$ to analyse the effect of the cation host on keratin solubility. These three ILs have dissolution trends identical to the predicted $\ln \gamma$ trends, and the cation host has a moderate impact on the dissolution process. In these three ionic liquids, 1) The effect of the number of heteroatoms in cation on keratin dissolution capability can be analyzed by the difference of 
keratin solubility between methylpyrrolidinium-based (BmpyrrCl) and methylimidazolium-based ILs (BmimCl); 2) The effect of the size of the ring in cations on keratin dissolution capability can be obtained by analyzing the difference of keratin solubility between Pyridinium-based (BpyCl) and methylpyrrolidinium-based ILs (BmpyrrCl).

Anion effect. To compare the influence of different anions on keratin dissolution, EmimAc, EmimDEP, EmimCl, BmimCl, BmimDCA and BmimSCN were used at $120^{\circ} \mathrm{C}$. Since $\mathrm{BmimCl}$ has a lower $\ln \gamma$ than that of BmimDCA and BmimSCN, higher keratin solubility in BmimCl compared to that of BmimDCA and BmimSCN was expected. The same rationale can be used to understand the different levels of keratin solubility for EmimAc vs. EmimDEP and EmimAc vs. EmimCl. Unexpectedly, EmimDEP had higher solubility than EmimCl, although its $\ln \gamma$ value was higher. This divergence between prediction and experimental results might be explained by that the ability for $\mathrm{H}$-bonds formation of $\mathrm{Cl}^{-}$is not clear and it is difficult to give a proper model in COSMO-RS. Kahlen et al. ${ }^{33}$ and Liu et al. ${ }^{22}$ also give identical interpretation to explain why experimental results and prediction data for ILs with chloride anion do not always agree. ${ }^{22,33} \mathrm{In}$ these verification experiments, the $\ln \gamma$ of ILs with different anions changed from -0.49 (GSSG) to -1.53 (GSSG), and the corresponding keratin solubility changes from $1 \mathrm{wt} \%$ to $38 \mathrm{wt} \%$, thus indicating that anions play the main role in the keratin dissolution process.

Summing up, anions play a leading role in keratin dissolution, while cations only have a moderate effect on the dissolution process. ILs with anions $\mathrm{Ac}^{-}, \mathrm{Dec}^{-}, \mathrm{HCOO}^{-}, \mathrm{Cl}^{-}, \mathrm{DEP}^{-}, \mathrm{DMP}^{-}$, $\mathrm{DBP}^{-}, \mathrm{BEN}^{-}, \mathrm{Br}^{-}$, or TOS${ }^{-}$have high keratin dissolution capability. However, it should be noted that the stability of ionic liquids plays an important role in their long-term application. ${ }^{34}$ In industrial applications, the solubility and stability of ionic liquids should be considered comprehensively when choosing ionic liquids as solvent. 
Table 2 Experimental solubility of wool keratin in ten ILs and In $\gamma$ prediction results for three keratin models

\begin{tabular}{|c|c|c|c|c|c|c|}
\hline \multirow[t]{2}{*}{ No. } & \multirow[t]{2}{*}{ ILs } & \multirow{2}{*}{$\begin{array}{l}\text { Solubility } \\
\left(\mathrm{wt}^{\circ} \%\right)\end{array}$} & \multirow{2}{*}{$\begin{array}{l}\text { Temperature } \\
{ }^{\circ} \mathrm{C}\end{array}$} & \multicolumn{3}{|c|}{$\ln \gamma$ prediction results at $120^{\circ} \mathrm{C}$} \\
\hline & & & & $\begin{array}{l}\text { CYS } \\
\text { model }\end{array}$ & $\begin{array}{l}\text { GSSG } \\
\text { model }\end{array}$ & $\begin{array}{l}\mathrm{PP} \\
\text { model }\end{array}$ \\
\hline $\mathrm{a}$ & EmimAc & 38 & 120 & -2.35 & -1.53 & -1.63 \\
\hline $\mathrm{b}$ & EmimDEP & 22 & 120 & -1.82 & -1.18 & -1.41 \\
\hline $\mathrm{c}$ & AmimCl & 13 & 120 & -1.89 & -1.27 & -1.40 \\
\hline $\mathrm{d}$ & EmimCl & 14 & 120 & -1.86 & -1.26 & -1.37 \\
\hline e & $\mathrm{BmimCl}$ & 11 & 120 & -1.85 & -1.25 & -1.41 \\
\hline $\mathrm{f}$ & HOEtmimCl & 3 & 120 & -1.46 & -1.03 & -1.14 \\
\hline g & BmimDCA & 1.5 & 120 & -0.79 & -0.55 & -0.66 \\
\hline $\mathrm{h}$ & BmimSCN & $<1$ & 120 & -0.67 & -0.49 & -0.56 \\
\hline $\mathrm{i}$ & BmpyrrCl & 40 & 180 & -2.10 & -1.38 & -1.56 \\
\hline $\mathrm{j}$ & $\mathrm{BpyCl}$ & 36 & 180 & -1.83 & -1.25 & -1.41 \\
\hline $\mathrm{k}$ & $\mathrm{BmimCl}$ & 35 & 180 & -1.85 & -1.25 & -1.41 \\
\hline
\end{tabular}

Keratin model effect. In order to check whether these keratin models are able to describe the keratin, the residual sum of squares (RSS) and $R$ square $\left(R^{2}\right)$ between the $\ln \gamma$ of the three keratin models and keratin solubility were analysed further. Figure 6 shows that the R squares $\left(\mathrm{R}^{2}\right)$ were 0.71, 0.66, 0.65 by using CYS, GSSG and PP as the keratin model, and the residual sum of squares (RSS) were $0.68,0.32$ and 0.37 , respectively. The $\mathrm{R}$ squares $\left(\mathrm{R}^{2}\right)$ of the three keratin models were similar, while the residual sum of squares for CYS was higher than for the other two models. These findings suggest that the $\ln \gamma$ of GSSG and PP are better correlated with the experimental keratin solubility results than that of CYS. As illustrated in the predicted $\ln \gamma$ of the three keratin models, 
the values of $\ln \gamma$ when using CYS are lower than for other two models, which might be due to the fact that the CYS model is too simple to represent keratin.

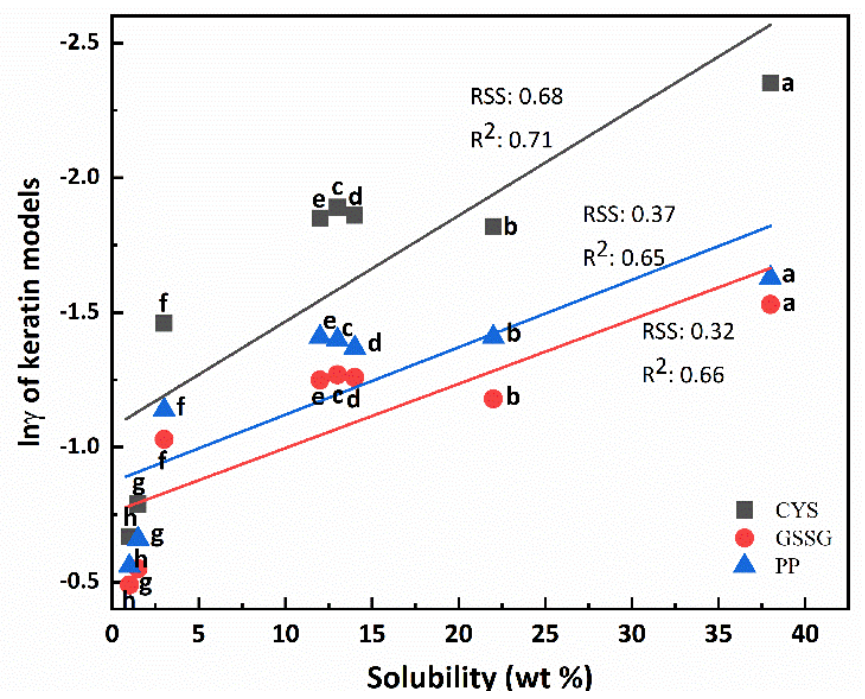

Figure 6. Experimental keratin solubility in ten ILs plotted against $\ln \gamma$ at $120^{\circ} \mathrm{C}$

\section{Prediction of $\sigma$-profiles}

$\sigma$-profiles can be used to analyse the dissolution capability of ILs. As such, the $\sigma$-profiles between the three keratin models and several cations and anions were also predicted by COSMORS. Figure 7 shows that the $\sigma$-profiles of $\mathrm{Ac}^{-}$and the three keratin models are almost overlapping in the H-bond donor, the non-polar and the H-bond acceptor regions. The same phenomenon is found in the $\sigma$-profiles of $\mathrm{DEP}^{-}$and the three keratin models. Nonetheless, the $\sigma$-profile overlap of $\mathrm{Ac}^{-}$and the three keratin models in the non-polar region is better than that of $\mathrm{DEP}^{-}$and the three keratin models, which means that ILs with $\mathrm{Ac}^{-}$have a higher keratin dissolution capability than the ILs with $\mathrm{DEP}^{-}$when they have the same cation. This result is also supported by the research of Liu et al. ${ }^{18}$ In addition, the $\sigma$-profiles of $\mathrm{DCA}^{-}$and the three keratin models are not particularly complementary in the non-polar and H-bond acceptor regions. From the verification experiment, EmimAc has a higher keratin dissolution capability than EmimDEP, and BmimDCA has a weak 
ability to dissolve keratin, which is consistent with the predicted result for $\sigma$-profiles and the logarithmic activity coefficient $(\ln \gamma)$ by COSMO-RS.

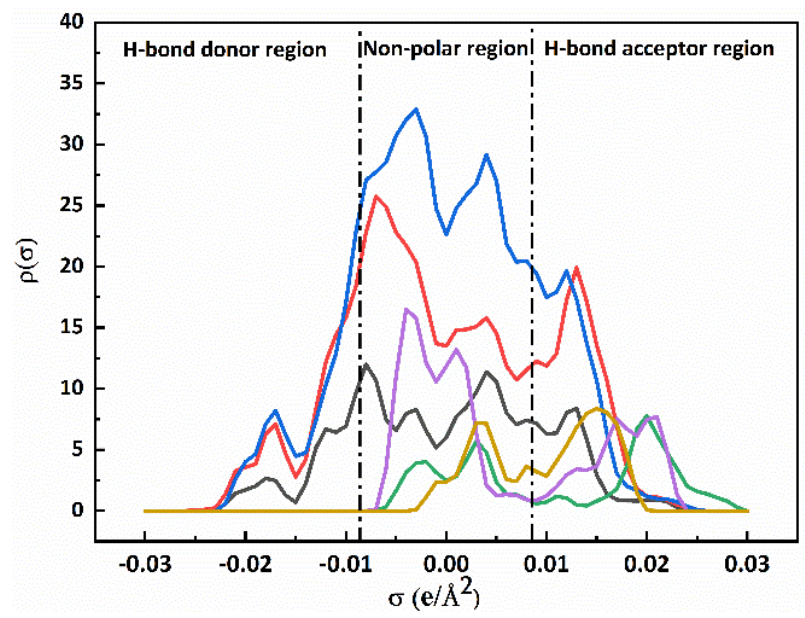

Figure 7. $\sigma$-profiles of the three keratin models: CYS (black line), GSSG (red line), PP (blue line) and anions $\mathrm{Ac}^{-}$(green line), $\mathrm{DEP}^{-}$(purple line) and $\mathrm{DCA}^{-}$(yellow line).

In order to study further the interactions of keratin models and cations, the $\sigma$-profiles of the three keratin models and several cations are compared in Figure 8. As evidenced in Fig. 8, the range of peaks in the $\sigma$-profile plots of $[\mathrm{Emim}]^{+},[\mathrm{Epy}]^{+}$and $[\text {Eemor }]^{+}$are similar, and the intensity of the peaks is slightly different, which indicates that ILs cations have a moderate effect on the dissolution process. This conclusion is also in agreement with the results for the predicted logarithmic activity coefficient $(\ln \gamma)$ and the verification experiment. The analysis of $\sigma$-profiles between the three keratin models and several cations and anions further indicates that anions play a leading role in keratin dissolution, and cations have a moderate influence on the keratin dissolution capability of ILs. 


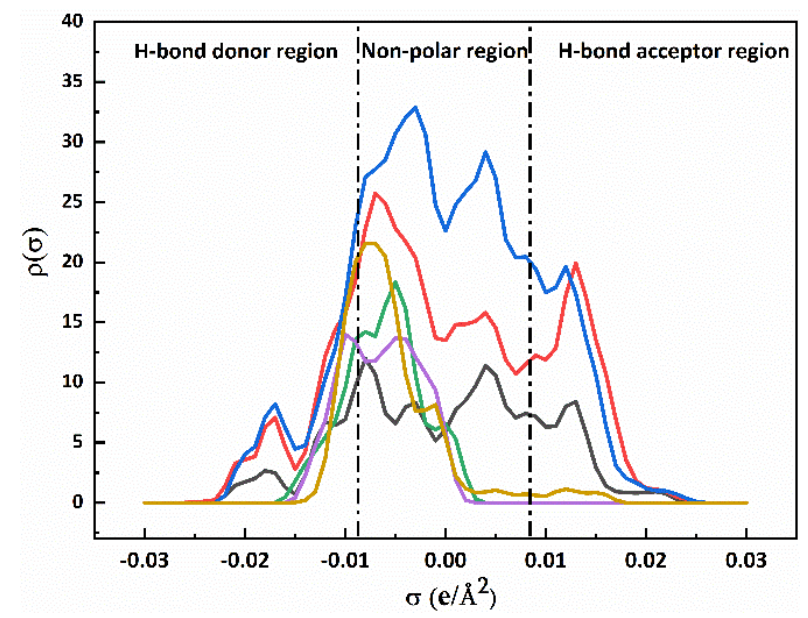

Figure 8. $\sigma$-profiles of three keratin models: CYS (black line), GSSG (red line), PP (blue line) and cations $[\text { Emim }]^{+}$(green line), $[\text {Epy }]^{+}$(purple line) and $[\text {Eemor }]^{+}$(yellow line).

\section{Predicting excess enthalpy}

Excess enthalpies between three keratin models and ten ILs were calculated, in order to explain further the possible interactions of keratin molecules and ILs structures. Combining the results presented in Fig. 9, Fig. 10 and Fig. 11, it is evident that the main forces in the keratin dissolution process in ILs are H-bonds, while the contributions of misfit forces and van der Waals forces are secondary, which was agreement with the viewpoint of Zhang et al. ${ }^{35}$ The reason for the difference between the solubility of HOEtmimCl and $\mathrm{EmimCl}$ is the formation of intramolecular H-bonds between ILs and keratin molecules, which leads to a drop of the ability to cleave H-bonds between keratin molecules, which again also support that the hydrogen bonding is the main force. Ji et al. ${ }^{36}$ investigated the extraction of keratin from feather by using ionic liquids and concluded that ILs are strong polar molecules that can break hydrogen bonds of keratin. Ghosh et al. ${ }^{37}$ reported that the chloride-containing IL was the best solvent of keratin among the ILs they tested, which can be due to the high concentration of $\mathrm{Cl}^{-}$and its nucleophilic activity exhibiting a strong effect on H-bonds. Moreover, the excess enthalpies of ILs with the same cations and different anions exhibit a big difference, which can be proven by the excess enthalpy differences between EmimAc, EmimDEP and EmimCl. This conclusion can also be drawn from the excess enthalpy differences between $\mathrm{BmimCl}, \mathrm{BmimDCA}$ and BmimSCN, albeit there is a slight difference between those of ILs with the same anions and different cations, such as the six ILs with $\mathrm{Cl}^{-}$shown in Figs. 9-11. This is in agreement with the deduction that anions play a crucial role in disrupting chemical interactions and therefore dissolution. 


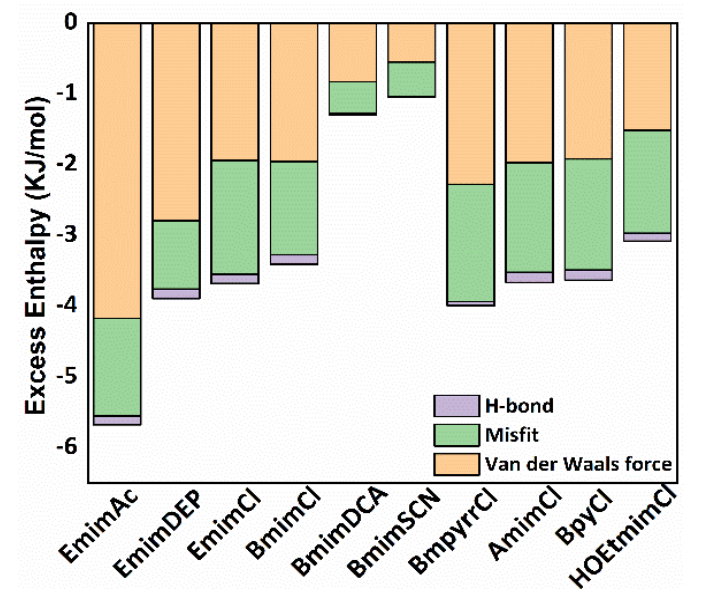

Figure 9. Excess enthalpies between the CYS keratin model and ten ILs

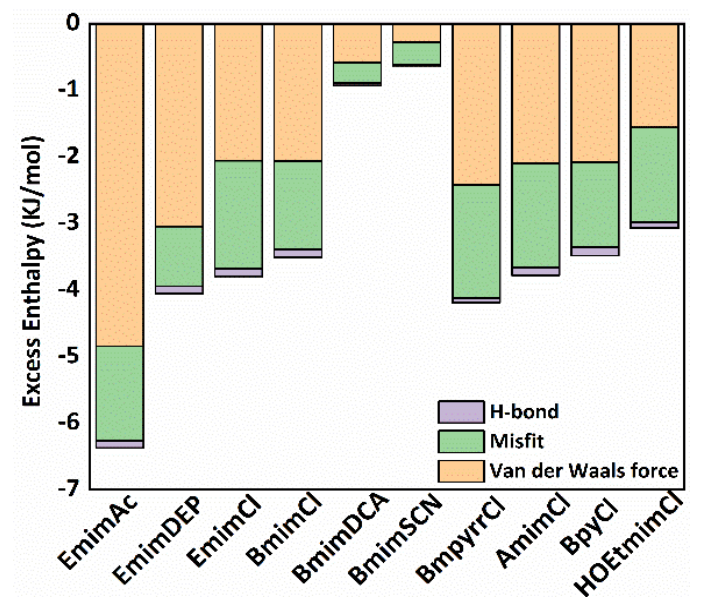

Figure 10. Excess enthalpies between the GSSG keratin model and ten ILs

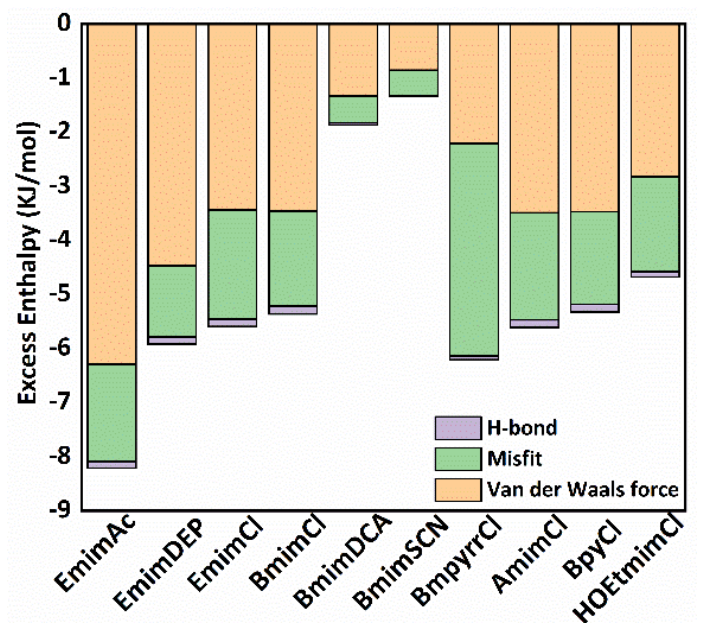

Figure 11. Excess enthalpies between the PP keratin model and ten ILs 


\section{CONCLUSIONS}

In summary, three keratin models were selected to represent keratin, and a screening method based on COSMO-RS was used to evaluate the keratin dissolution capability of ILs. Prediction results for the logarithmic activity coefficient $(\ln \gamma)$ indicate that anions play a major role in the keratin dissolution process, while cations have a moderate effect on the keratin dissolution capability of ILs. In particular, the hydroxyl group in cations has an important influence on the solubility of keratin in ILs. $\mathrm{Ac}^{-}$, $\mathrm{Dec}^{-}, \mathrm{HCOO}^{-}, \mathrm{Cl}^{-}, \mathrm{BEN}^{-}, \mathrm{DMP}^{-}, \mathrm{DEP}^{-}, \mathrm{DBP}^{-}, \mathrm{TOS}^{-}$and $\mathrm{Br}^{-}$, with the various cations studied in this work, exhibited particularly good properties for keratin dissolution.

The experimental solubility of ten ILs was in accordance with that of the prediction $\ln \gamma$, thereby indicating that the prediction value of $\ln \gamma$ via COSMO-RS can effectively reflect the keratin dissolution capability of ILs. Furthermore, the GSSG and PP keratin models are better at describing keratin than the CYS options. Finally, our excess enthalpy calculations indicated that H-bonds play a main role in the keratin dissolution process, followed by misfit forces and van der Waals forces.

\section{ASSOCIATED CONTENT}

Supporting Information: The contents of supporting information are water content of ten ILs, ${ }^{1} \mathrm{H}$ NMR, ${ }^{13} \mathrm{C}$ NMR and Electronic spray mass spectrum of three synthetic ILs, Literature values of keratin dissolution in ILs, Logarithmic activity coefficients of three keratin models.

\section{AUTHOR INFORMATION}

\section{Corresponding Author}

*Prof. Suojiang Zhang $\quad$ E-mail: sjzhang@ipe.ac.cn 
*Prof. Anne Ladegaard Skov E-mail: $\underline{\text { al@kt.dtu.dk }}$

\section{Notes}

The authors declare no competing financial interest.

\section{ACKNOWLEDGEMENTS}

We sincerely thank Wenhui Tu for a great deal of helpful advice in the calculation of COSMORS. This work was supported by the Department of Chemical and Biochemical Engineering, Technical University of Denmark, the National Natural Science Foundation of China (21576262 and 21776276) and Beijing Municipal Naturel Science Foundation. 


\section{REFERENCES}

1. Lee, H.; Hwang, Y.-S.; Lee, H.-S.; Choi, S.; Kim, S. Y.; Moon, J.-H.; Kim, J. H.; Kim, K. C.; Han, D.-W.; Park, H.-J., Human hair keratin-based biofilm for potent application to periodontal tissue regeneration. Macromol. Res. 2015, 23 (3), 300-308, DOI 10.1007/s13233015-3036-y.

2. Shavandi, A.; Silva, T. H.; Bekhit, A. A.; Bekhit, A. E.-D. A., Keratin: dissolution, extraction and biomedical application. Biomater. Sci.-UK 2017, 5 (9), 1699-1735, DOI 10.1039/C7BM00411G.

3. Rouse, J. G.; Van Dyke, M. E., A review of keratin-based biomaterials for biomedical applications. Materials 2010, 3 (2), 999-1014, DOI 10.3390/ma3020999.

4. Xie, H.; Li, S.; Zhang, S., Ionic liquids as novel solvents for the dissolution and blending of wool keratin fibers. Green Chem. 2005, 7 (8), 606, DOI 10.1039/b502547h.

5. Li, R.; Wang, D., Preparation of regenerated wool keratin films from wool keratin-ionic liquid solutions. J. Appl. Polym. Sci. 2013, 127 (4), 2648-2653, DOI 10.1002/app.37527.

6. Zheng, S.; Nie, Y.; Zhang, S.; Zhang, X.; Wang, L., Highly efficient dissolution of wool keratin by dimethylphosphate ionic liquids. ACS Sustain. Chem. Eng. 2015, 3 (11), 29252932, DOI 10.1021/acssuschemeng.5b00895.

7. Idris, A.; Vijayaraghavan, R.; Rana, U. A.; Patti, A.; MacFarlane, D., Dissolution and regeneration of wool keratin in ionic liquids. Green Chem. 2014, 16 (5), 2857-2864, DOI 10.1039/C4GC00213J.

8. Idris, A.; Vijayaraghavan, R.; Rana, U. A.; Fredericks, D.; Patti, A.; MacFarlane, D., Dissolution of feather keratin in ionic liquids. Green Chem. 2013, 15 (2), 525-534, DOI 10.1039/C2GC36556A. 
9. Block, R. J., Chemical classification of keratins. Ann. N.Y. Acad. Sci. 1951, 53 (3), 608-612, DOI 10.1111/j.1749-6632.

10. Rhodes, H.; Potter, B.; Widra, A., Characteristics of the alpha-keratose fraction of hair inducing ascosporogenesis in Nannizzia Grubyia. Mycopathologia et mycologia applicata 1967, 33 (3-4), 345-348, DOI 101007/BF02088925.

11. Bang, E.-K.; Lista, M.; Sforazzini, G.; Sakai, N.; Matile, S., Poly (disulfide) s. Chem. Sci. 2012, 3 (6), 1752-1763, DOI 10.1039/C2SC20098H.

12. Cecil, R.; McPhee, J., The sulfur chemistry of proteins. In Adv. Protein Chem. 1959, 14, 255389, DOI 10.1016/S0065-3233(08)60613-0.

13. Idris, A.; Vijayaraghavan, R.; Patti, A.; MacFarlane, D., Distillable protic ionic liquids for keratin dissolution and recovery. ACS Sustain. Chem. Eng. 2014, 2 (7), 1888-1894, DOI $10.1021 /$ sc500229a.

14. Chen, Q.; Xu, A.; Li, Z.; Wang, J.; Zhang, S., Influence of anionic structure on the dissolution of chitosan in 1-butyl-3-methylimidazolium-based ionic liquids. Green Chem. 2011, 13 (12), 3446-3452, DOI 10.1039/C1GC15703E.

15. Shimo, M.; Abe, M.; Ohno, H., Functional comparison of polar ionic liquids and onium hydroxides for chitin dissolution and deacetylation to chitosan. ACS Sustain. Chem. Eng. 2016, 4 (7), 3722-3727, DOI 10.1021/acssuschemeng.6b00368.

16. Plowman, J. E.; Clerens, S.; Lee, E.; Harland, D. P.; Dyer, J. M.; Deb-Choudhury, S., Ionic liquid-assisted extraction of wool keratin proteins as an aid to MS identification. Anal. Methods 2014, 6 (18), 7305-7311, DOI 10.1039/C4AY01251H.

17. Zhang, Z.; Nie, Y.; Zhang, Q.; Liu, X.; Tu, W.; Zhang, X.; Zhang, S., Quantitative change in disulfide bonds and microstructure variation of regenerated wool keratin from various ionic 
liquids. ACS Sustain. Chem. Eng. 2017, 5 (3), 2614-2622, DOI 10.1021/acssuschemeng. $6 \mathrm{~b} 02963$.

18. Liu, X.; Nie, Y.; Meng, X.; Zhang, Z.; Zhang, X.; Zhang, S., DBN-based ionic liquids with high capability for the dissolution of wool keratin. RSC $A d v$. 2017, 7 (4), 1981-1988, DOI 10.1039/C6RA26057H.

19. Zhang, H.; Wu, J.; Zhang, J.; He, J., 1-Allyl-3-methylimidazolium chloride room temperature ionic liquid: a new and powerful nonderivatizing solvent for cellulose. Macromolecules 2005, $38(20), 8272-8277$, DOI 10.1021/ma0505676.

20. Loschen, C.; Klamt, A., Prediction of solubilities and partition coefficients in polymers using COSMO-RS. Ind. Eng. Chem. Res. 2014, 53 (28), 11478-11487, DOI 10.1021/ie501669z.

21. Guo, Z.; Lue, B.-M.; Thomasen, K.; Meyer, A. S.; Xu, X., Predictions of flavonoid solubility in ionic liquids by COSMO-RS: experimental verification, structural elucidation, and solvation characterization. Green Chem. 2007, 9 (12), 1362-1373, DOI 10.1039/B709786G.

22. Liu, Y.-R.; Thomsen, K.; Nie, Y.; Zhang, S.-J.; Meyer, A. S., Predictive screening of ionic liquids for dissolving cellulose and experimental verification. Green Chem. 2016, 18 (23), 6246-6254, DOI 10.1039/C6GC01827K.

23. Matheswaran, P.; Wilfred, C. D.; Kurnia, K. A.; Ramli, A., Overview of activity coefficient of thiophene at infinite dilution in ionic liquids and their modeling using COSMO-RS. Ind. Eng. Chem. Res. 2016, 55 (3), 788-797, DOI 10.1021/acs.iecr.5b04152.

24. AlSaleem, S. S.; Zahid, W. M.; AlNashef, I. M.; Hadj-Kali, M. K., Solubility of halogenated hydrocarbons in hydrophobic ionic liquids: experimental study and COSMO-RS prediction. J. Chem. Eng. Data 2015, 60 (10), 2926-2936, DOI 10.1021/acs.jced.5b00310. 
25. Paduszyński, K., An overview of the performance of the COSMO-RS approach in predicting the activity coefficients of molecular solutes in ionic liquids and derived properties at infinite dilution. Phys. Chem. Chem. Phys. 2017, 19 (19), 11835-11850, DOI 10.1039/C7CP00226B.

26. Casas, A.; Palomar, J.; Alonso, M. V.; Oliet, M.; Omar, S.; Rodriguez, F., Comparison of lignin and cellulose solubilities in ionic liquids by COSMO-RS analysis and experimental validation. Ind. Crops Prod. 2012, 37 (1), 155-163, DOI 10.1016/j.indcrop.2011.11.032.

27. Kuzmina, O.; Bhardwaj, J.; Vincent, S. R.; Wanasekara, N. D.; Kalossaka, L. M.; Griffith, J.; Potthast, A.; Rahatekar, S.; Eichhorn, S. J.; Welton, T., Superbase ionic liquids for effective cellulose processing from dissolution to carbonisation. Green Chem. 2017, 19 (24), 59495957, DOI 10.1039/C7GC02671D.

28. Nie, Y.; Li, C.; Sun, A.; Meng, H.; Wang, Z., Extractive desulfurization of gasoline using imidazolium-based phosphoric ionic liquids. Energ. Fuel. 2006, 20 (5), 2083-2087, DOI 10.1021/ef060170i.

29. Qiu, B.; Pan, C.; Qian, W.; Peng, Y.; Qiu, L.; Yan, F., Nitrogen-doped mesoporous carbons originated from ionic liquids as electrode materials for supercapacitors. J. Mater. Chem. A 2013, 1 (21), 6373-6378, DOI 10.1039/C3TA10774D.

30. Dharaskar, S. A.; Wasewar, K. L.; Varma, M. N.; Shende, D. Z., Synthesis, characterization, and application of 1-butyl-3-methylimidazolium thiocyanate for extractive desulfurization of liquid fuel. Environ. Sci. Pollut. R. 2016, 23 (10), 9284-9294, DOI 10.1016/j.arabjc. 2013.09.034.

31. Feng, L.; Chen, Z.-1., Research progress on dissolution and functional modification of cellulose in ionic liquids. J. Mol. Liq. 2008, 142 (1-3), 1-5, DOI 10.1016/j.molliq. 2008.06.007. 
32. Wang, Y.-X.; Cao, X.-J., Extracting keratin from chicken feathers by using a hydrophobic ionic liquid. Process Biochem. 2012, 47 (5), 896-899, DOI 10.1016/j.procbio.2012.02.013.

33. Kahlen, J.; Masuch, K.; Leonhard, K., Modelling cellulose solubilities in ionic liquids using COSMO-RS. Green Chem. 2010, 12 (12), 2172-2181, DOI 10.1039/C0GC00200C.

34. Cao, Y.; Mu, T., Comprehensive investigation on the thermal stability of 66 ionic liquids by thermogravimetric analysis. Ind. Eng. Chem. Res. 2014, 53 (20), 8651-8664, DOI 10.1021/ie5009597.

35. Zhang, S.; Huo, F., Angstrom science: Exploring aggregates from a new viewpoint. Green Energy Environ. 2016, l (1), 75-78, DOI 10.1016/j.gee.2016.04.008.

36. Ji, Y.; Chen, J.; Lv, J.; Li, Z.; Xing, L.; Ding, S., Extraction of keratin with ionic liquids from poultry feather. Sep. Purif. Technol. 2014, 132, 577-583, DOI 10.1016/j.seppur.2014.05.049.

37. Ghosh, A.; Clerens, S.; Deb-Choudhury, S.; Dyer, J. M., Thermal effects of ionic liquid dissolution on the structures and properties of regenerated wool keratin. Polym. Degrad. Stab. 2014, 108, 108-115, DOI 10.1016/j.polymdegradstab.2014.06.007. 
For table of contents

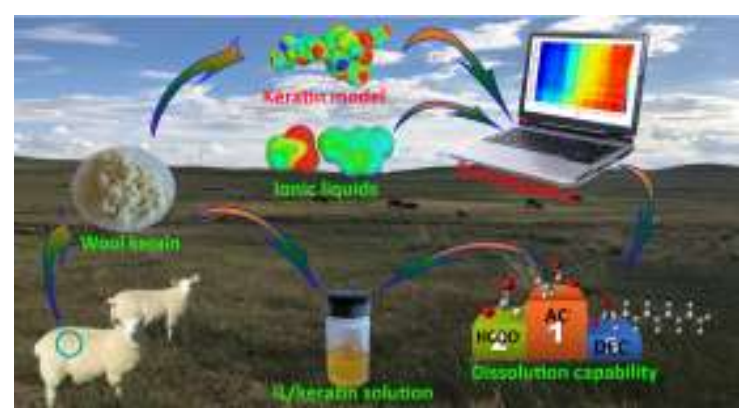

Synopsis:

Herein, three keratin models and 621 ILs, including 27 cations and 23 anions, were used to evaluate keratin dissolution capability via a screening method based on COSMO-RS. 


\title{
Supporting information
}

\section{Screening of ionic liquids for keratin dissolution by means of COSMO-RS and experimental verification}

\author{
Xue Liu ${ }^{\dagger, t}$, Yi Nie ${ }^{\dagger}$, Yanrong Liu', Suojiang Zhang ${ }^{* \dagger}$, Anne Ladegaard Skov ${ }^{*+}$
}

${ }^{\dagger}$ Beijing Key Laboratory of Ionic Liquids Clean Process, Key Laboratory of Green Process and Engineering, State Key Laboratory of Multiphase Complex Systems, Institute of Process Engineering, Chinese Academy of Sciences, P.O. Box 353 Beijing, 100190, China.

${ }^{ \pm}$Danish Polymer Centre, Department of Chemical and Biochemical Engineering, Technical University of Denmark, Søltofts Plads 227, 2800 Lyngby, Denmark.

Corresponding Author: E-mail: $\underline{\text { al@kt.dtu.dk, sjzhang@ipe.ac.cn }}$

Number of pages: 9

Number of figures: 4

Number of tables: 5 


\section{Synthesis and characterization of ILs}

\subsection{Properties of ten ILs}

Table S1. Properties of ten ILs

\begin{tabular}{|c|c|c|c|c|}
\hline ILs & $\operatorname{cation}(\mathbf{m} / \mathbf{z})$ & $\operatorname{negion}(\mathbf{m} / \mathbf{z})$ & $\begin{array}{l}\text { Water } \\
\text { content }(\mathbf{p p m})\end{array}$ & Purity \\
\hline EmimAc & 111.0931 & --- & 2890 & $99 \%$ \\
\hline EmimDEP & 111.0917 & 153.0311 & 1310 & --- \\
\hline AmimCl & 123.0930 & --- & 2508 & $99 \%$ \\
\hline EmimCl & 111.0931 & --- & 1163 & $98 \%$ \\
\hline BmimCl & 139.1247 & --- & 2727 & $98 \%$ \\
\hline HOEtmimCl & 127.0896 & --- & 9001 & $99 \%$ \\
\hline BmimDCA & 139.1253 & --- & 4237 & --- \\
\hline BmimSCN & 139.1264 & --- & 2606 & --- \\
\hline BmpyrrCl & 142.1629 & --- & 9661 & $99 \%$ \\
\hline BpyCl & 136.1158 & --- & 2200 & $99 \%$ \\
\hline
\end{tabular}

1.2 NMR analysis and Electronic spray mass spectrum of three synthesis ILs

EmimDEP: ${ }^{1} \mathrm{H}$ NMR (d 6 -DMSO): 9.32[s, 1H, (Im)], 7.86[t, J=1.7 Hz, 1H, (Im)], 7.76[t, $\mathrm{J}=1.6 \mathrm{~Hz}, 1 \mathrm{H},(\mathrm{Im})], 4.23\left[\mathrm{q}, \mathrm{J}=7.3 \mathrm{~Hz}, 2 \mathrm{H}, \mathrm{CH}_{2}-\mathrm{CH}_{3}\right], 3.88\left[\mathrm{~s}, 3 \mathrm{H}, \mathrm{N}-\mathrm{CH}_{3}\right], 3.62[\mathrm{p}, \mathrm{J}=7.0 \mathrm{~Hz}$, $4 \mathrm{H}, 2(\mathrm{O}-\mathrm{CH} 2)], 1.40\left[\mathrm{t}, \mathrm{J}=7.3 \mathrm{~Hz}, 3 \mathrm{H}, \mathrm{CH}_{2}-\mathrm{CH}_{3}\right], 1.07[\mathrm{t}, \mathrm{J}=7.1 \mathrm{~Hz}, 6 \mathrm{H}, 2(\mathrm{O}-\mathrm{CH} 2-\mathrm{CH} 3)] ;{ }^{13} \mathrm{C}$ NMR: $136.86,123.51,121.94,58.98,43.98,35.55,16.68,15.14$. 
BmimSCN: ${ }^{1} \mathrm{H}$ NMR (d 6 -DMSO): 9.10[d, J=1.9 Hz, 1H, (Im)], 7.77[d, J=1.9 Hz, 1H, (Im)], $7.70[\mathrm{~d}, \mathrm{~J}=1.9 \mathrm{~Hz}, 1 \mathrm{H},(\mathrm{Im})], 3.85\left[\mathrm{~s}, \mathrm{~J}=7.3 \mathrm{~Hz}, 2 \mathrm{H}, \mathrm{N}-\mathrm{CH}_{2}-\right], 3.34\left[\mathrm{~s}, 3 \mathrm{H}, \mathrm{N}-\mathrm{CH}_{3}\right], 1.76[\mathrm{~m}$, $\left.\mathrm{J}=7.3 \mathrm{~Hz}, 2 \mathrm{H},-\mathrm{CH}_{2}-\mathrm{CH}_{2}-\mathrm{CH}_{3}\right], 1.26\left[\mathrm{q}, \mathrm{J}=7.4 \mathrm{~Hz}, 2 \mathrm{H}, \mathrm{CH}_{2}-\mathrm{CH}_{3}\right], 0.90\left[\mathrm{t}, \mathrm{J}=7.4 \mathrm{~Hz}, 3 \mathrm{H},-\mathrm{CH}_{3}\right]$; ${ }^{13}$ C NMR: $136.67,123.95,122.52,48.97,36.26,31.80,18.93,13.41$.

BmimDCA: ${ }^{1} \mathrm{H}$ NMR (d $\left.6^{-D M S O}\right): 9.10[\mathrm{~d}, \mathrm{~J}=1.7 \mathrm{~Hz}, 1 \mathrm{H},(\mathrm{Im})], 7.76[\mathrm{t}, \mathrm{J}=1.8 \mathrm{~Hz}, 1 \mathrm{H},(\mathrm{Im})]$, $7.70[\mathrm{t}, \mathrm{J}=1.9 \mathrm{~Hz}, 1 \mathrm{H},(\mathrm{Im})], 3.84\left[\mathrm{t}, \mathrm{J}=7.3 \mathrm{~Hz}, 2 \mathrm{H}, \mathrm{N}-\mathrm{CH}_{2}-\right], 3.31\left[\mathrm{~s}, 3 \mathrm{H}, \mathrm{N}-\mathrm{CH}_{3}\right], 1.76[\mathrm{~m}, \mathrm{~J}=7.3$ $\left.\mathrm{Hz}, 2 \mathrm{H},-\mathrm{CH}_{2}-\mathrm{CH}_{2}-\mathrm{CH}_{3}\right], 1.25\left[\mathrm{~m}, \mathrm{~J}=7.1 \mathrm{~Hz}, 2 \mathrm{H}, \mathrm{CH}_{2}-\mathrm{CH}_{3}\right], 0.90\left[\mathrm{t}, \mathrm{J}=7.4 \mathrm{~Hz}, 3 \mathrm{H},-\mathrm{CH}_{3}\right] ;{ }^{13} \mathrm{C}$ NMR: 137.12, 123.80, 122.74, 48.97, 36.26, 31.64, 18.93, 13.41.

\section{Electronic spray mass spectrum}

\section{EmimDEP:}

Cation:

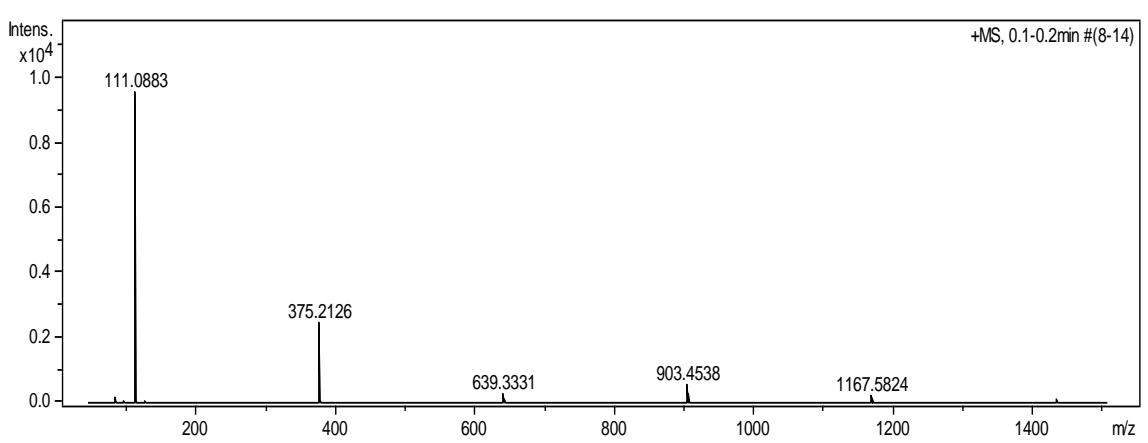

Figure S1. Electronic spray mass spectrum of [Emim] ${ }^{+}$

Anion:

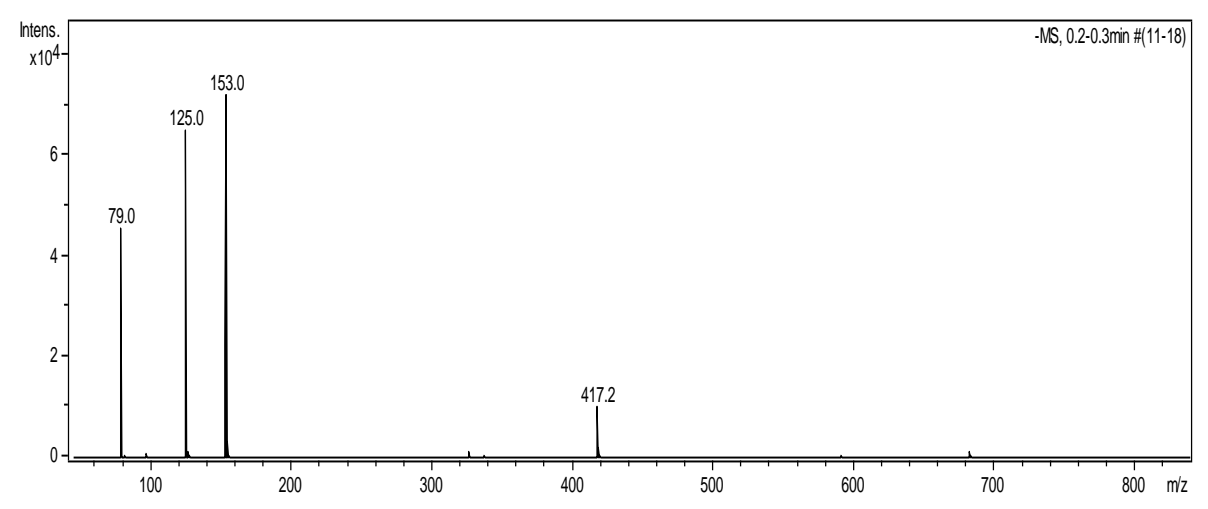

Figure S2. Electronic spray mass spectrum of [DEP] 


\section{BmimDCA:}

Cation:

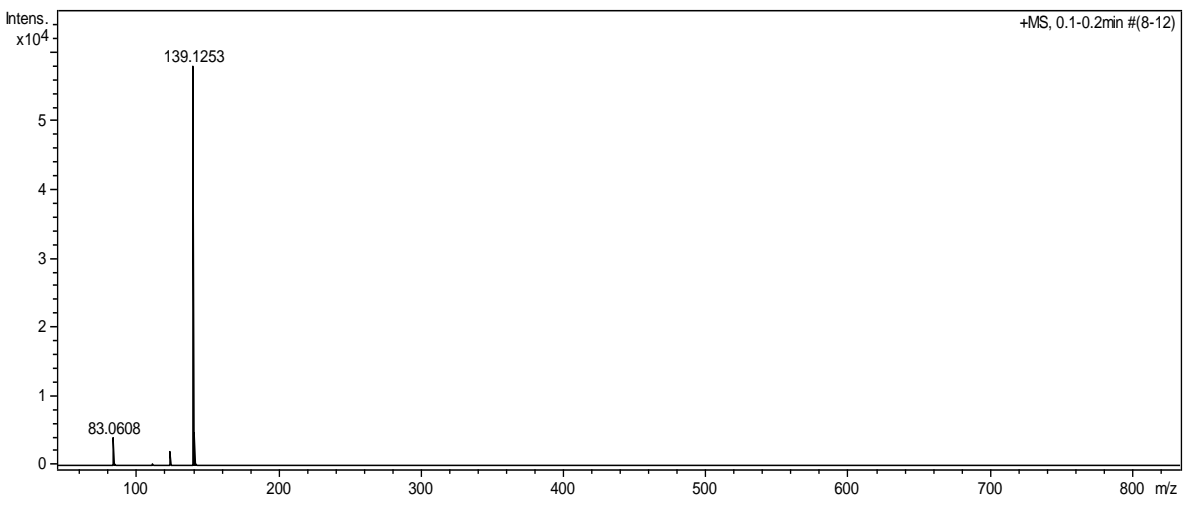

Figure S3. Electronic spray mass spectrum of [Bmim]+

\section{BmimSCN:}

\section{Cation:}

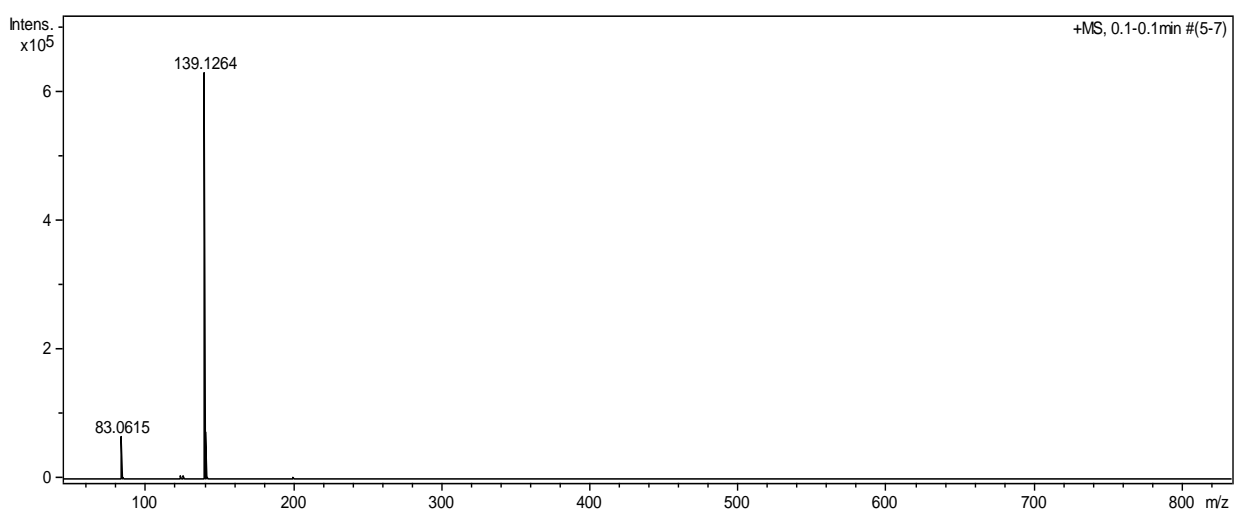

Figure S4. Electronic spray mass spectrum of $[\mathrm{Bmim}]^{+}$ 
2. Literature values of keratin dissolution in ionic liquids

Table of $\mathbf{S 2}$ The literature values of keratin dissolution in ionic liquids

\begin{tabular}{|c|c|c|c|c|c|c|c|}
\hline \multirow[b]{2}{*}{ Material } & \multirow[b]{2}{*}{ ILs } & \multicolumn{6}{|c|}{ Conditions } \\
\hline & & $\begin{array}{c}\text { Temperature } \\
\left({ }^{\circ} \mathrm{C}\right)\end{array}$ & Solid:liquid & Time & $\begin{array}{c}\text { Solubility } \\
(\mathbf{w t} \%)\end{array}$ & $\begin{array}{l}\text { Yield of } \\
\text { keratin }\end{array}$ & Ref \\
\hline Wool & AmimCl & 130 & -- & $640 \mathrm{~min}$ & $21 \%$ & -- & $1^{1}$ \\
\hline Wool & $\mathrm{BmimCl}$ & 130 & -- & $535 \mathrm{~min}$ & $15 \%$ & -- & 1 \\
\hline Wool & $\mathrm{BmimCl}$ & 120 & $1: 6$ & $30 \mathrm{~min}$ & -- & $57 \%$ & $2^{2}$ \\
\hline Wool & $\mathrm{BmimCl}$ & 150 & $1: 6$ & 30min & -- & $35 \%$ & 2 \\
\hline Wool & $\mathrm{BmimCl}$ & 180 & $1: 6$ & 30min & -- & $18 \%$ & 2 \\
\hline Feathers & $\mathrm{BmimCl}$ & 130 & $1: 2$ & $10 \mathrm{~h}$ & $50 \%$ & $60 \%$ & $3^{3}$ \\
\hline Feathers & $\mathrm{AmimCl}$ & 130 & $1: 2$ & $10 \mathrm{~h}$ & $50 \%$ & $60 \%$ & 3 \\
\hline Feathers & $\begin{array}{l}\text { Choline } \\
\text { thioglycolate }\end{array}$ & 130 & $1: 2$ & $10 \mathrm{~h}$ & $45 \%$ & $55 \%$ & 3 \\
\hline Wool & BmimOAc & 130 & $1: 12.5$ & $10 \mathrm{~min}$ & -- & -- & $4^{4}$ \\
\hline Wool & BmimSCN & 130 & $1: 12.5$ & $900 \mathrm{~min}$ & -- & -- & 4 \\
\hline Wool & $\mathrm{BmimFeCl}_{4}$ & 130 & $1: 12.5$ & $\mathrm{nd}^{\mathrm{a}}$ & -- & -- & 4 \\
\hline Wool & BmimDMP & 130 & $1: 12.5$ & $90 \mathrm{~min}$ & -- & -- & 4 \\
\hline Wool & EmimDMP & 130 & $1: 12.5$ & $90 \mathrm{~min}$ & -- & -- & 4 \\
\hline Wool & $\mathrm{BmimCl}$ & 130 & $1: 12.5$ & $300 \mathrm{~min}$ & -- & -- & 4 \\
\hline Wool & $\mathrm{P}_{4444} \mathrm{Cl}$ & 130 & $1: 12.5$ & $\mathrm{nd}^{\mathrm{a}}$ & -- & -- & 4 \\
\hline Wool & $\mathrm{N}_{4444} \mathrm{Cl}$ & 130 & $1: 12.5$ & $\mathrm{nd}^{\mathrm{a}}$ & -- & -- & 4 \\
\hline Wool & $\mathrm{N}_{2221} \mathrm{DMP}$ & 130 & $1: 12.5$ & $180 \mathrm{~min}$ & -- & -- & 4 \\
\hline Wool & EmimDEP & 120 & $1: 12.5$ & $90 \mathrm{~min}$ & -- & $0.3553 \mathrm{~g} / \mathrm{g}$ & $5^{5}$ \\
\hline Wool & EmimDMP & 120 & $1: 12.5$ & $150 \mathrm{~min}$ & -- & $0.3118 \mathrm{~g} / \mathrm{g}$ & 5 \\
\hline Wool & DBNEDEP & 120 & $1: 12.5$ & $180 \mathrm{~min}$ & -- & $0.4471 \mathrm{~g} / \mathrm{g}$ & 5 \\
\hline Wool & DBNMDMP & 120 & $1: 12.5$ & $210 \mathrm{~min}$ & -- & $0.4000 \mathrm{~g} / \mathrm{g}$ & 5 \\
\hline Wool & DBNHOAc & 120 & $1: 12.5$ & $30 \mathrm{~min}$ & -- & $0.1697 \mathrm{~g} / \mathrm{g}$ & 5 \\
\hline
\end{tabular}




\section{Logarithmic activity coefficients of three keratin models}

Table S3. Prediction In $\gamma$ of CYS by COMSO-RS

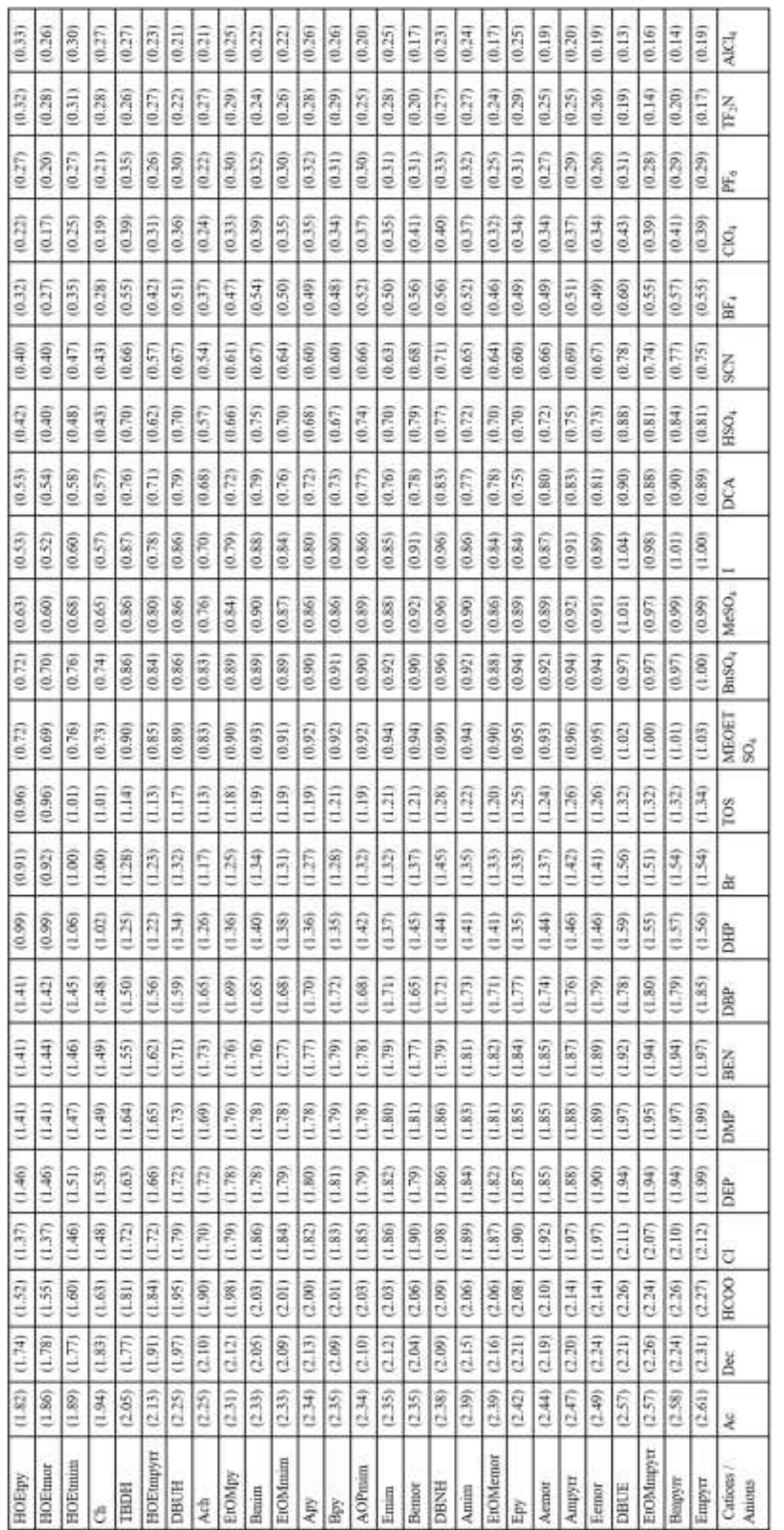


Table S4. Prediction In $\gamma$ of GSSG by COMSO-RS

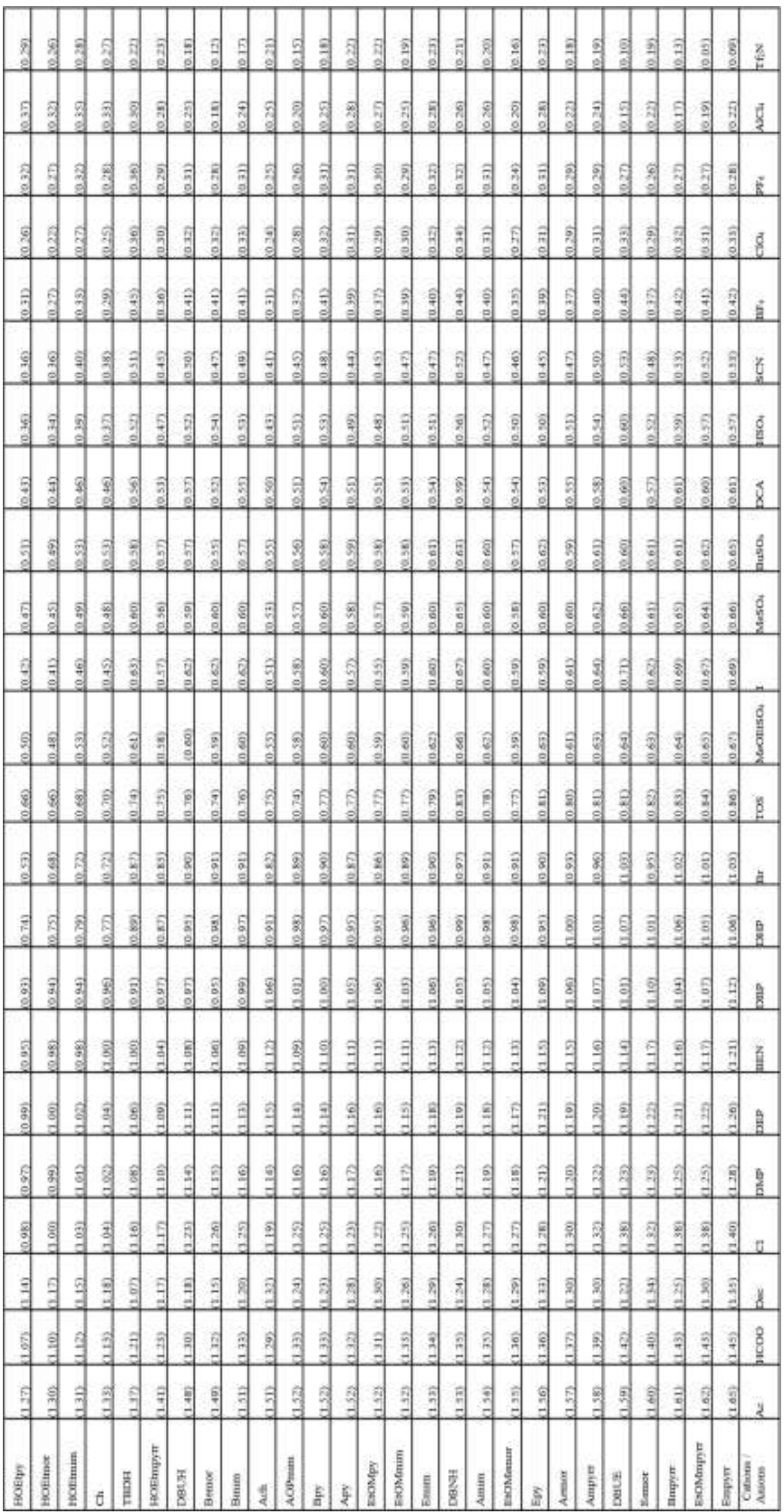


Table S5. Prediction In $\gamma$ of PP by COMSO-RS

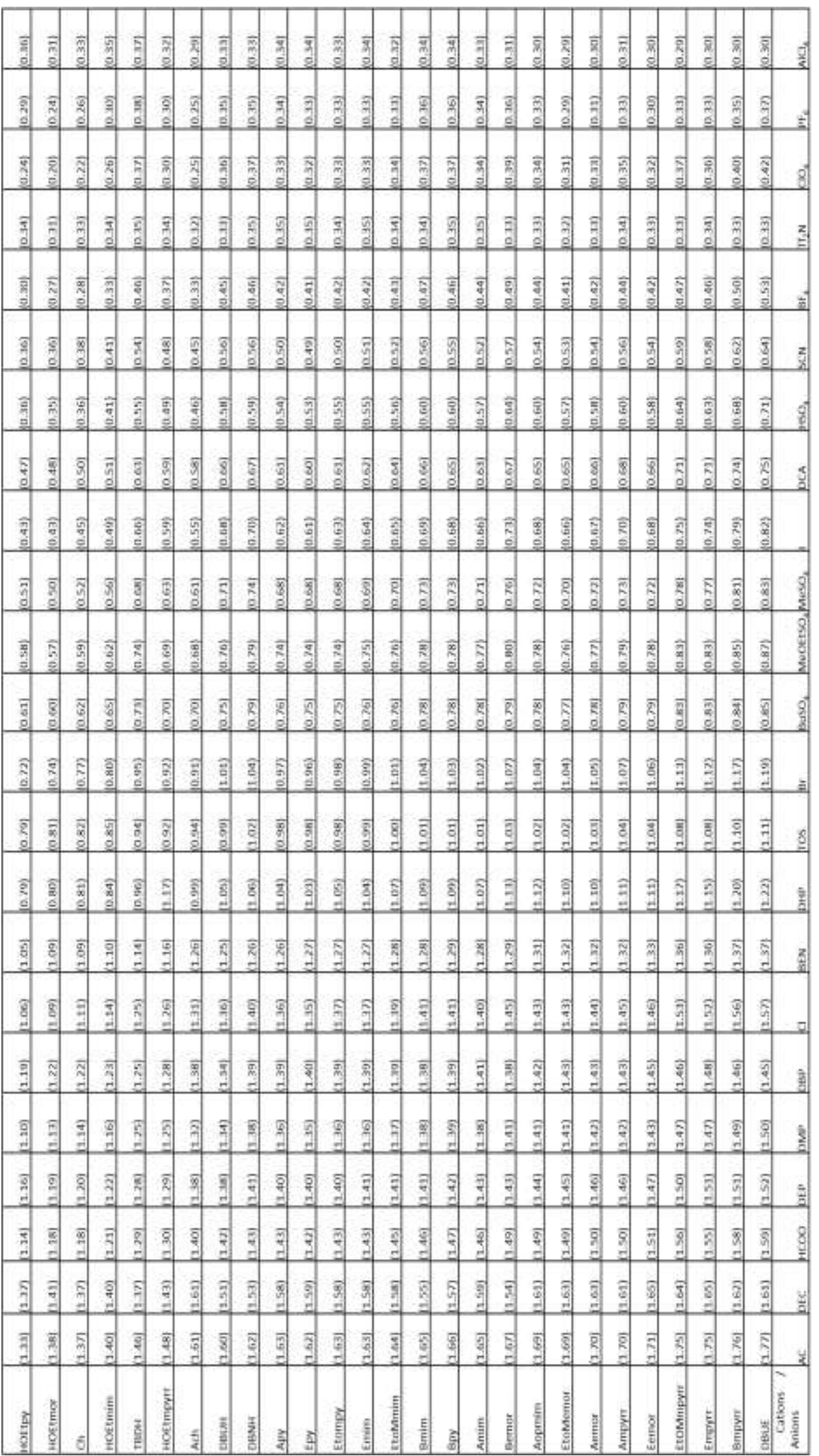




\section{REFERENCES}

1. Li, R.; Wang, D., Preparation of regenerated wool keratin films from wool keratin-ionic liquid solutions. J. Appl. Polym. Sci. 2013, 127 (4), 2648-2653.

2. Ghosh, A.; Clerens, S.; Deb-Choudhury, S.; Dyer, J. M., Thermal effects of ionic liquid dissolution on the structures and properties of regenerated wool keratin. Polym. Degrad. Stab. 2014, 108, 108-115.

3. Idris, A.; Vijayaraghavan, R.; Rana, U. A.; Fredericks, D.; Patti, A.; MacFarlane, D., Dissolution of feather keratin in ionic liquids. Green Chem. 2013, 15 (2), 525-534.

4. Zheng, S.; Nie, Y.; Zhang, S.; Zhang, X.; Wang, L., Highly efficient dissolution of wool keratin by dimethylphosphate ionic liquids. ACS Sustain. Chem. Eng. 2015, 3 (11), 2925-2932.

5. Liu, X.; Nie, Y.; Meng, X.; Zhang, Z.; Zhang, X.; Zhang, S., DBN-based ionic liquids with high capability for the dissolution of wool keratin. RSC Adv. 2017, 7 (4), 19811988. 
